\title{
Contribution of Countries to Main Neurosurgical Journals with Particular Emphasis on Turkey
}

\author{
Can SARICA ${ }^{1}$, Emrah EGEMEN² \\ ${ }^{1}$ Adiyaman University Education and Research Hospital, Department of Neurosurgery, Adiyaman, Turkey \\ ${ }^{2}$ Pamukkale University, Department of Neurosurgery, Denizli, Turkey
}

Corresponding author: Can SARICA can.sarica@gmail.com

\section{ABSTRACT}

AIM: To quantitatively analyze the contribution of different countries to neurosurgical journals, with emphasis on Turkey. Further, we discuss the factors affecting research productivity and strategies for improvement.

MATERIAL and METHODS: Neurosurgical journals were selected from the Journal Citation Reports database using given criteria. Data were collected from the Web of Science database to analyze the contribution rates of countries to neurosurgical journals in terms of publication numbers and average citations per item from September to December 2018. The article types, departmental contributions, and most cited articles were evaluated particularly for Turkey.

RESULTS: Fourteen of 52 journals were chosen for analysis. There were 82,626 articles published from 2000 to 2018 . The top three contributors included the USA with 28,939 (35\%), Japan with 6,382 (7.7\%), and Germany with 4,454 articles (5.3\%). Turkey contributed 2,087 articles (2.5\%) to neurosurgical journals, including 1003 (48\%) original articles and 742 (36\%) case reports, and ranked 10th in the world. Hacettepe University is the only organization in Turkey that ranked in the top 10 in all categories. Among the top-cited articles from Turkey, the majority were retrospective studies (39\%), followed by laboratory studies (18\%) and prospective studies (15\%).

CONCLUSION: This bibliometric assessment of neurosurgical journals allows countries to perceive their neurosurgical research productivity. It can function as a benchmark for academic productivity and the methodology can be a model for particular analysis of other countries.

KEYWORDS: Bibliometrics, Citation, Neurosurgery, Neurosurgical journals, Research

\section{INTRODUCTION}

$\mathrm{N}$ eurosurgery entered into the modern era over a century ago and it has been continuously developing ever since (14). This development has been achieved by the collective efforts of neurosurgeons all over the world and has proceeded without interruption to better serve an estimated 22.6 million patients per year worldwide that suffer from a neurosurgical disorder (10).

Scientific research is the major key for this development, and it has helped define the way that the discipline is practiced by serving as the foundation for methodology, procedures, or concepts $(5,11,15)$. Nevertheless, research has a cost
(19). Besides the monetary costs, such as research funding, operating costs of a research facility, and lost workdays of voluntary research subjects, there are also monetarily nonquantifiable costs like time expenses of clinicians. We believe these research costs have to be equitably borne among all countries of the world and should not be the burden of one or two countries. Contribution to the collective global knowledge base must be cross-national and cross-cultural. Turkey has been contributing for a long time to this knowledge, but the extent of this contribution has only been assessed in detail in very few studies $(3,4,11,22)$.

With these considerations, we aimed to evaluate the scientific productivity of Turkey in the main neurosurgical journals 
using novel detailed methodology and discuss the possible strategies to improve this contribution.

\section{MATERIAL and METHODS}

This study was a retrospective bibliometric analysis of two databases, i.e., Clarivate Analytics's Web of Science (WOS) and Incites Journal Citation Reports (JCR), and was exempt from institutional review board approval.

\section{Identification of Neurosurgical Journals and Their Classification}

We searched the JCR database for publications with the words "neurosurgery," "neurosurgical," "surgical neurology," "neurochirurgica," "neurochirurgia," "neurochirurgie," "neurocirugia," "nervous," "neurological," and "spine" to identify journals specifically dedicated to neurosurgical topics. A total of 52 journals were found. The websites, editorial boards and published articles of each were checked to exclude the ones that were not related to neurosurgery. We separated the journals into five categories according to their scope; (1) general neurosurgery; (2) spinal neurosurgery; (3) pediatric neurosurgery; (4) functional neurosurgery, and (5) skull base surgery (Table I). We did not find any journals that were particularly dedicated to neurosurgical oncology and cerebrovascular neurosurgery.

We excluded the journals mentioned below and provide the reasons in parenthesis;

1. Journals with a JCR Impact Factor that was below 2.0 in 5 years, except the ones that fit in Categories 3, 4, and 5

2. Neurosurgery Clinics of North America, and Neurosurgical Review (mostly review articles instead of original research)

3. Neurosurgical Focus (only accepting articles on particular topics that were determined for each issue)

4. Journal of Neurology Neurosurgery and Psychiatry, Neurological Sciences, Journal of the Neurological Sciences, CNS and Neurological Disorders-Drug Targets, Therapeutic Advances in Neurological Disorders (mostly neurology, psychiatry and neuroscience topics)

5. Joint Bone Spine (mostly orthopedics topics)

\section{Evaluation of Contributions to the Main Neurosurgical Journals by Country}

Searches for journals, both alone and together, that were in the same category, were performed by "publication name"

Table I: Journal List

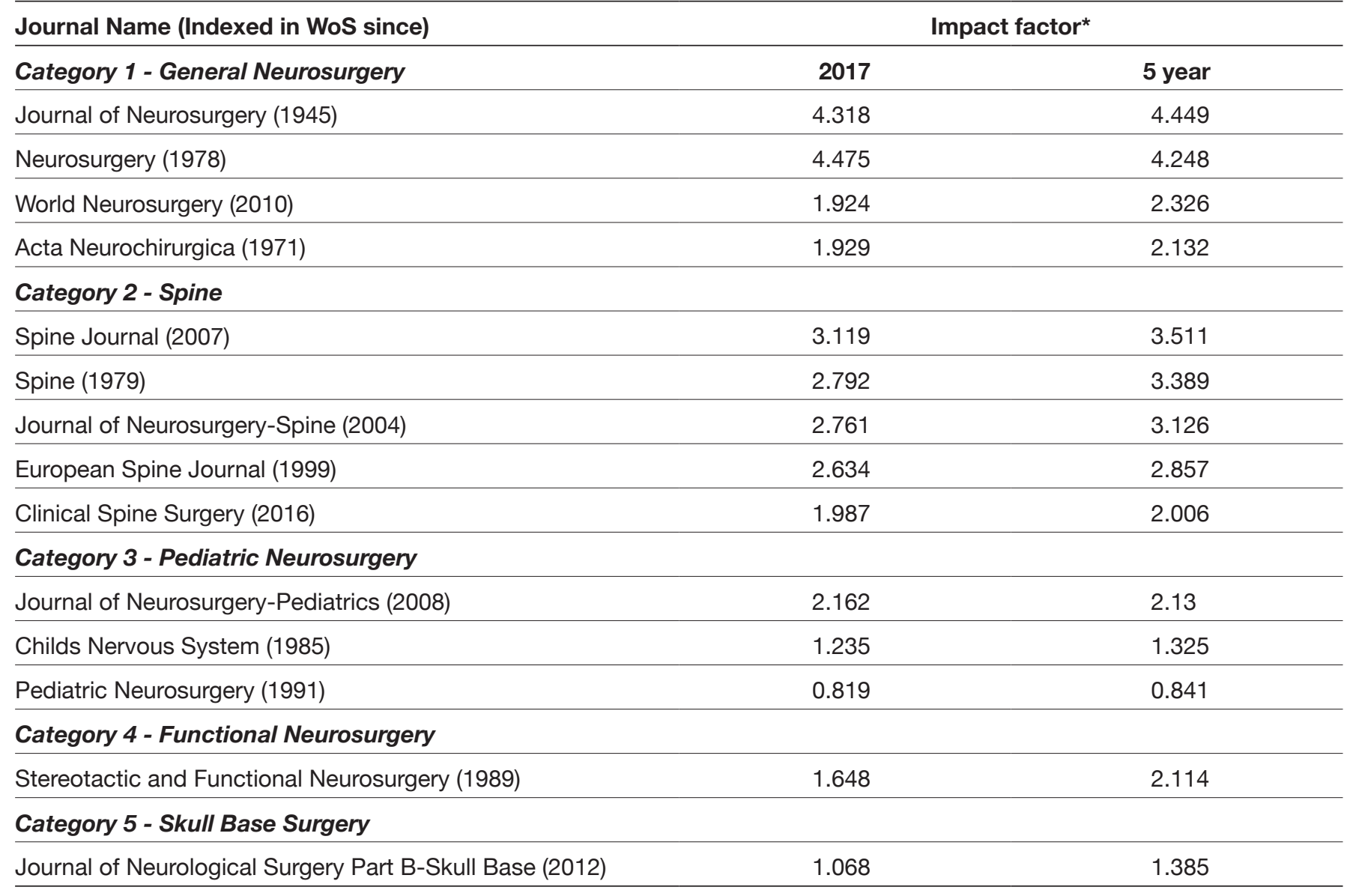

* Data from the 2017 edition of Journal Citation Reports. WoS: Web of Science Database. 
using the WOS database. The results were refined via selecting the publication years. Two time periods (2000 to 2018 and 2016 to 2018) were analyzed. To evaluate the contributions by country in terms of publication number, we first selected the "Analyze Results" section, and then the "Countries/Regions" tab. The analysis was done automatically by the WOS database using the address field for all authors in each article. Because some articles were multinational, the sum of the publication numbers of each country was greater than the count of the total published articles. In the case of an equal number of publications between countries, we used the average citation count per item for ranking. Searches were done on September 3, 2018 for Categories 4 and 5; September 7, 2018 for Category 1; September 10, 2018 for Category 2; and December 27, 2018 for Category 3. To calculate the average citation count for each country, countries were selected one by one in the aforementioned tab and a citation report was created for each.

Article types were classified into five categories; that is, as "Original Articles," including laboratory investigations, clinical and anatomical studies, technical notes, doing more with less, peer-review reports; "Case Reports," including case reports, case-based updates, case illustrations, case reports and literature reviews, and images; "Review Articles"; "Letter to Editors"; and "Others," including historical vignettes, perspectives, brief communications, forums, focus sessions, cover pictures, presidential addresses, commentaries, corrections, biographies, and legacy and editorial messages. The article type was decided after evaluation of the full text of the article, and double-checked using the MEDLINE database and website for each journal.

\section{Evaluation of the Contributions of the Institutions in Turkey}

For further evaluation of the articles from Turkey, "Turkey" was selected and viewed in the previously described section. Articles from Turkey were re-analyzed using the "Analyze Results" section again. The "Organizations-Enhanced" tab was selected for evaluation of the contributed departments. All publications from all institutions were analyzed one by one regarding article type, duplications and errors by the authors.

Ranking of the institutions was done according to the highest number of publications for each category. In the case of an equal number of publications between institutions, we used the average citation count per item for ranking. Instead of combining the results of different medical faculties of the same university, as with the WOS archiving system, we separated the universities with two medical faculties and evaluated each medical faculty separately. Publications that were written by the faculties other than in a medical department (e.g., veterinary faculties) were added to the publication counts of the oldest medical faculty of that university. Universities that had hospitals in different cities were also separated and each hospital in each city was analyzed separately. Some organizations that had a name change were evaluated together with their previous name. The list of universities and hospitals that were separated differently in this study and how they were separated is given in Table II.

\section{Determination of the Highest Cited Articles from Turkey}

A citation report was created in the WOS database for all articles from Turkey, and the 10 top-cited articles for each category were noted. Citation counts for these articles from SCOPUS and Google Scholar databases were also noted. Data on citations were obtained on September 4, 2018 and articles with citations below 10 were excluded.

Table II: List of Universities and Hospitals that were Separated Differently than the WOS Database

Name of the Organization as Indexed by WOS

\begin{tabular}{lcc}
\hline Istanbul University & Istanbul Uni - Cerrahpasa & \\
\hline Gulhane Military Medical Academy & Istanbul Uni - Istanbul & \\
\hline Baskent University & Gulhane Acad - Ankara & Gulhane Training Research Hospital (TRH) \\
\hline \multicolumn{4}{l}{ Gulhane Acad - Haydarpasa } & Istanbul Haydarpasa Sultan Abdulhamid TRH \\
\hline Baskent Uni - Ankara & \\
\hline Baskent Uni - Istanbul & \\
\hline Belcuk University & Baskent Uni - Alanya & \\
\hline Baskent Uni - Adana & \\
\hline & Meram Med Sch* & Secmettin Erbakan Uni \\
\hline
\end{tabular}

*: Older medical faculty. WOS: Web of Science. 


\section{RESULTS}

\section{Evaluation of Contributions by Country and a Particular Analysis for Turkey}

The contribution of countries to each category in terms of publication number, together with the average citation count per item is given in Figure 1. Between the years 2000-2018, the top 3 countries contributing to neurosurgical journals were the USA (31\%), Japan (7\%) and Germany (5\%) for category 1; USA (40\%), Japan (9\%) and China (8\%) for category 2; USA $(37 \%)$, Turkey $(6 \%)$ and Canada $(6 \%)$ for category 3 ; USA (37\%), Japan (9\%) and Germany (6\%) for category 4; USA
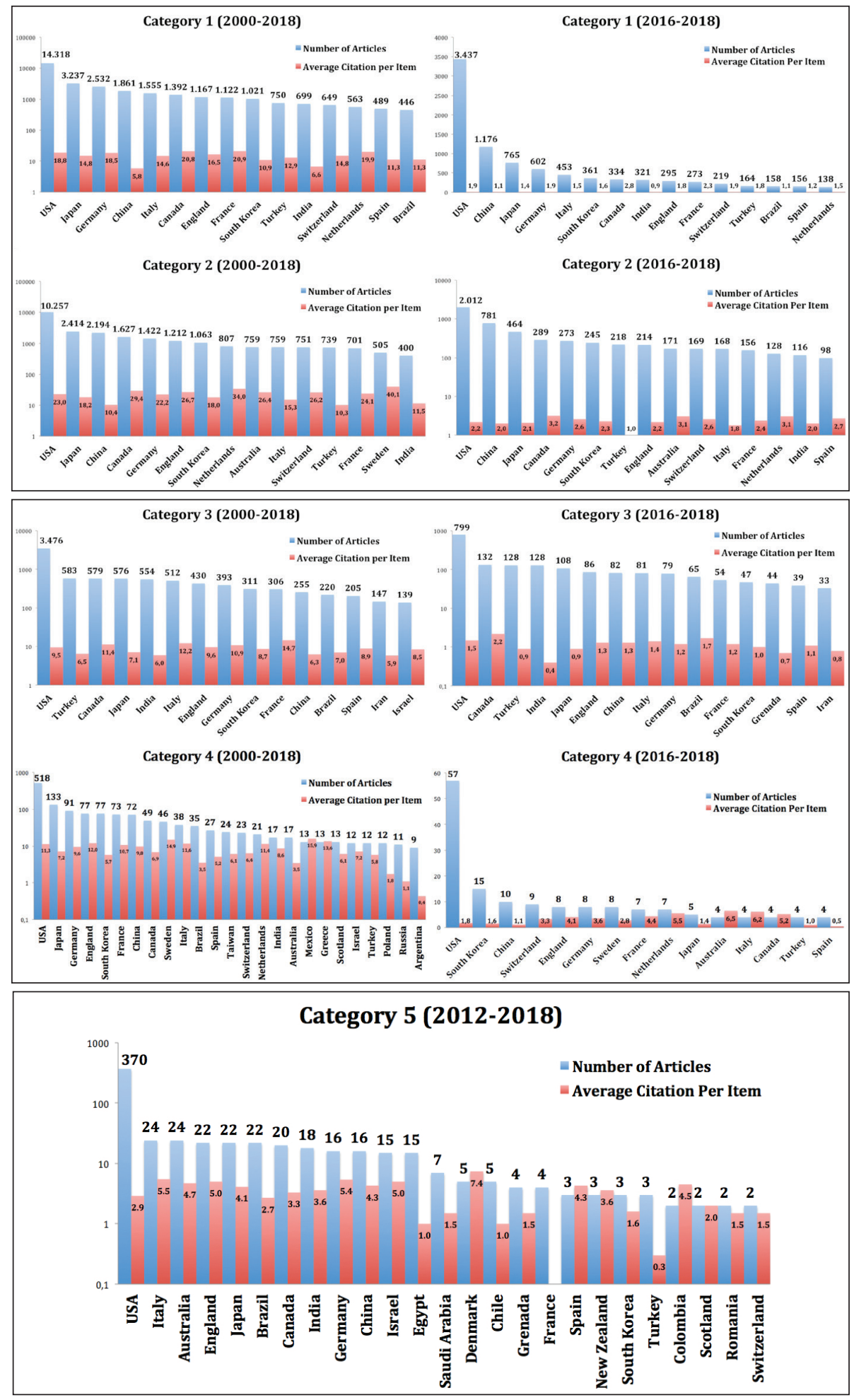

Figure 1: The contribution of countries to each category in terms of publication number, and the average citation count per item. 
(68\%), Italy (4\%), and Australia (4\%) for category 5. Turkey was ranked $10^{\text {th }}, 12^{\text {th }}, 2^{\text {nd }}, 22^{\text {nd }}$, and $21^{\text {st }}$ among all countries in Categories 1, 2, 3, 4, and 5, respectively.

Among the 82,626 publications in all the journals between 2000 and 2018, 2,087 (2.5\%) of them were contributed by authors from Turkey, of which 1,003 (48\%) were original articles and $742(36 \%)$ were case reports, and Turkey ranked 10 th in the world in terms of publication number in the studied journals (Table III). Figure 2 summarizes the yearly world rank and contribution percentage of Turkey among all journals in all categories. The USA is the top contributing country for all the selected journals with 28,939 (35\%) publications. The contribution rates of all countries are given in Figure 3.

Table III: Number and Types of Publications

\begin{tabular}{|c|c|c|c|c|c|c|c|c|c|}
\hline \multirow[t]{2}{*}{ Journal Name } & \multicolumn{2}{|c|}{ 2016-2018 } & \multicolumn{7}{|c|}{$2000-2018$} \\
\hline & $\begin{array}{l}\text { Total \# of } \\
\text { Art. }\end{array}$ & $\begin{array}{c}\text { Cont. of } \\
\text { Turkey }\end{array}$ & $\begin{array}{l}\text { Total \# } \\
\text { of Art. }\end{array}$ & $\begin{array}{l}\text { Cont. of } \\
\text { Turkey }\end{array}$ & Original & Case & Rev & Letter & Other \\
\hline \multicolumn{10}{|l|}{ Category 1} \\
\hline JNS & 2213 & 20 (0.9\%) & 13697 & $196(1.4 \%)$ & $89(45 \%)$ & $55(28 \%)$ & - & 47 (24\%) & $5(3 \%)$ \\
\hline Neurosurgery & 1628 & $4(0.2 \%)$ & 17481 & $128(0.7 \%)$ & $82(64 \%)$ & $22(17 \%)$ & $3(2 \%)$ & $1(1 \%)$ & $20(16 \%)$ \\
\hline $\begin{array}{l}\text { World } \\
\text { Neurosurgery }\end{array}$ & 5227 & 125 (2.3\%) & 8274 & $168(2 \%)$ & $105(63 \%)$ & $24(14 \%)$ & $5(3 \%)$ & $17(10 \%)$ & $17(10 \%)$ \\
\hline $\begin{array}{l}\text { Acta } \\
\text { Neurochirurgica }\end{array}$ & 995 & 15 (1.5\%) & 6873 & $258(3.7 \%)$ & $136(53 \%)$ & 67 (26\%) & $14(5 \%)$ & $31(12 \%)$ & $10(4 \%)$ \\
\hline Total & 10063 & 164 (1.6\%) & 46325 & 750 (1,6\%) & $412(55 \%)$ & $168(22 \%)$ & $22(3 \%)$ & $96(13 \%)$ & 52 (7\%) \\
\hline \multicolumn{10}{|l|}{ Category 2} \\
\hline Spine Journal & 968 & 145 (15\%) & 3446 & 277 (8\%) & $28(10 \%)$ & 245 (89\%) & $1(0 \%)$ & $2(1 \%)$ & $1(0 \%)$ \\
\hline Spine & 1387 & $24(1.7 \%)$ & 11630 & 196 (1.6\%) & 145 (74\%) & 35 (18\%) & $2(1 \%)$ & $11(6 \%)$ & $3(1 \%)$ \\
\hline JNS-Spine & 700 & $3(0.4 \%)$ & 3497 & 90 (2.5\%) & $60(67 \%)$ & $14(15 \%)$ & - & $15(17 \%)$ & $1(1 \%)$ \\
\hline $\begin{array}{l}\text { European Spine } \\
\text { Journal }\end{array}$ & 1459 & $39(2.6 \%)$ & 6047 & 169 (2.7\%) & 118 (70\%) & $33(20 \%)$ & $6(3 \%)$ & $9(5 \%)$ & $3(2 \%)$ \\
\hline $\begin{array}{l}\text { Clinical Spine } \\
\text { Surgery }\end{array}$ & 566 & $7(1.2 \%)$ & 566 & $7(1.2 \%)$ & 7 (100\%) & - & - & - & - \\
\hline Total & 5080 & $218(4.2 \%)$ & 25186 & $739(2.9 \%)$ & 358 (49\%) & 327 (44\%) & $9(1 \%)$ & $37(5 \%)$ & $8(1 \%)$ \\
\hline \multicolumn{10}{|l|}{ Category 3} \\
\hline JNS-Pediatrics & 686 & $7(1 \%)$ & 2637 & $32(1.2 \%)$ & $10(31 \%)$ & 15 (47\%) & - & $5(16 \%)$ & 2 (6\%) \\
\hline $\begin{array}{l}\text { Childs Nervous } \\
\text { System }\end{array}$ & 1052 & $101(9.6 \%)$ & 4865 & 386 (7.9\%) & 154 (40\%) & 129 (33\%) & $8(2 \%)$ & $42(11 \%)$ & $53(14 \%)$ \\
\hline $\begin{array}{l}\text { Pediatric } \\
\text { Neurosurgery }\end{array}$ & 200 & 20 (10\%) & 1685 & 165 (9.8\%) & 57 (34\%) & $100(61 \%)$ & - & $7(4 \%)$ & $1(1 \%)$ \\
\hline Total & 1938 & $128(6.6 \%)$ & 9187 & $583(6.3 \%)$ & $221(38 \%)$ & $244(42 \%)$ & $8(1 \%)$ & $54(9 \%)$ & $56(10 \%)$ \\
\hline \multicolumn{10}{|l|}{ Category 4} \\
\hline SFN & 138 & $4(2.8 \%)$ & 1389 & $12(0.8 \%)$ & $9(75 \%)$ & $3(25 \%)$ & - & - & - \\
\hline \multicolumn{10}{|l|}{ Category 5} \\
\hline JNLS-B & 261 & $3(1.1 \%)$ & 539 & $3(0.5 \%)$ & $3(100 \%)$ & - & - & - & - \\
\hline Overall & 17480 & $517(2.9 \%)$ & 82626 & 2087 (2.5\%) & 1003 (48\%) & $742(36 \%)$ & $39(2 \%)$ & 187 (9\%) & $116(5 \%)$ \\
\hline
\end{tabular}

JNS: Journal of Neurosurgery, SFN: Stereotactic and functional neurosurgery, JNLS-B: Journal of Neurological Surgery Part B-Skull Base, Total \# of Art.: Total number of published articles, Cont. of Turkey: Contribution of Turkey, Original: Original articles, Case: Case reports, Rev: Review articles, Letter: Letter to editors. 


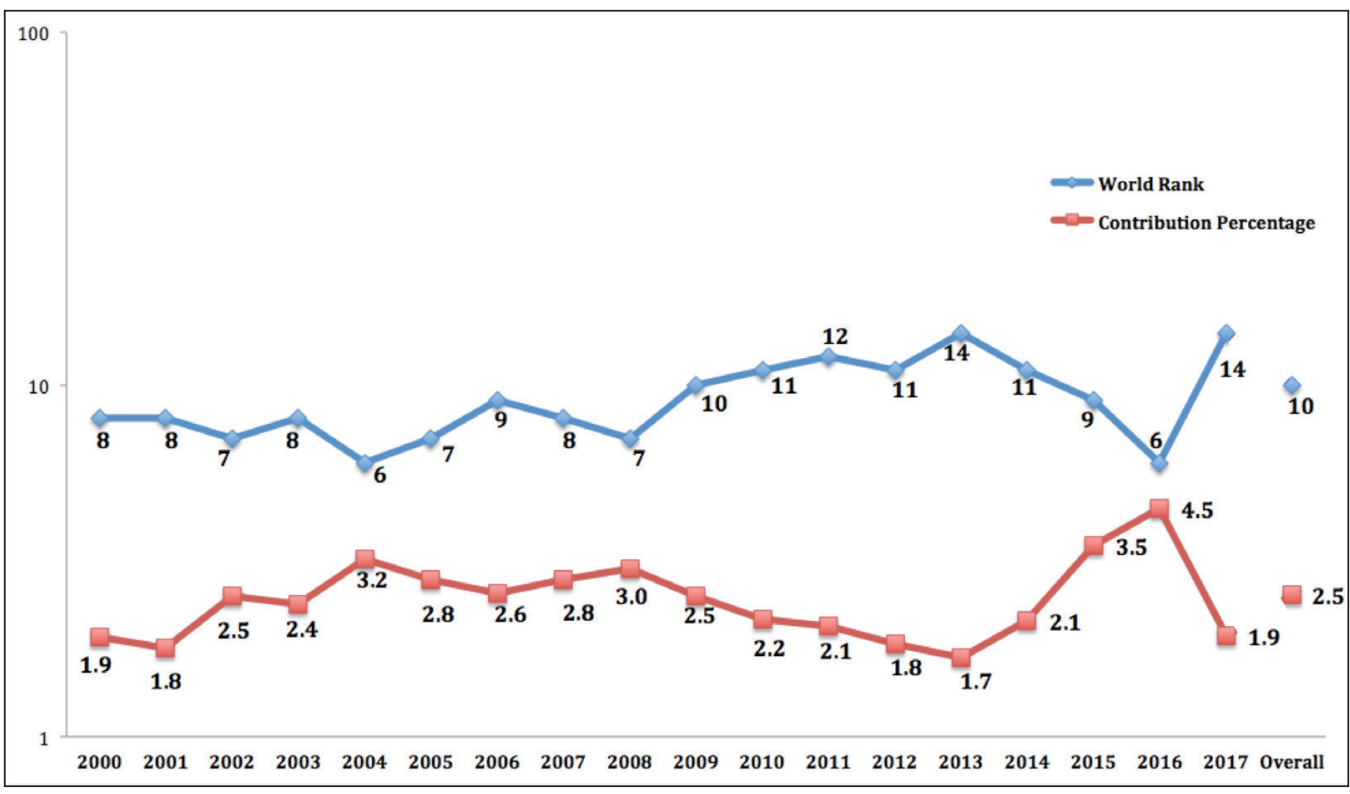

Figure 2: Turkey's world rank and percentage of contributions to main neurosurgical journals over years between 2000 and 2017.

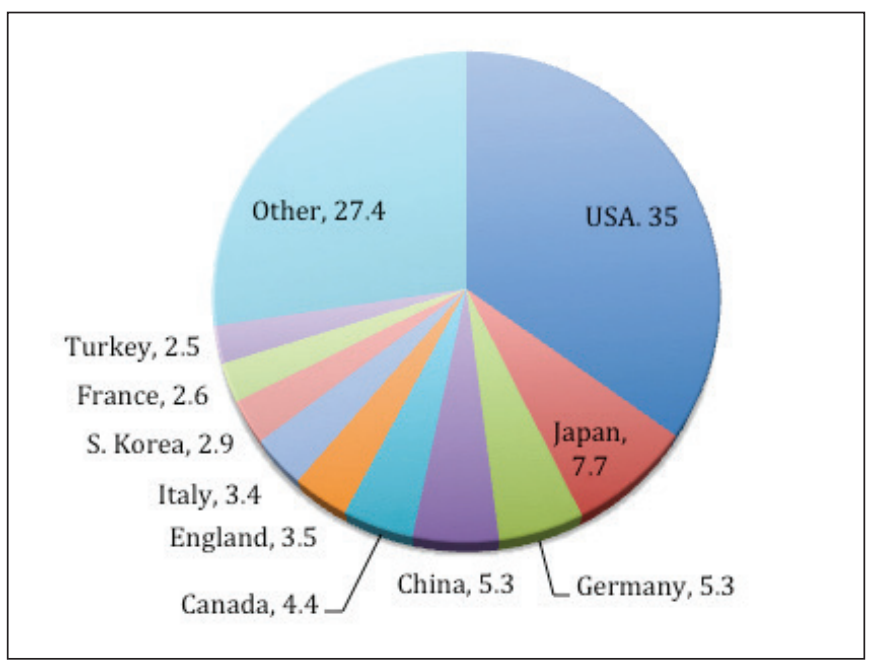

Figure 3: The contribution percentages of countries to main neurosurgical journals.

\section{Evaluation of the Contribution of the Institutions in Turkey}

Hacettepe University was the only organization that ranked in the top 10 in all categories. While Ankara University ranked in the top 10 in 4 categories, Marmara, Gazi, and Bahcesehir Universities ranked in the top 10 in 3 categories. Hacettepe University was ranked $1^{\text {st }}$ in categories 1 and 2 with 70 and 93 publications, respectively; and it was ranked $2^{\text {nd }}$ in category 3 with 55 publications only after Ege University, which published 65 papers in this category. In category 4, Pamukkale University was the leading university with 5 publications (Table IV). Some likely mistakes found in the WOS archiving system are given in Table II.

\section{Determination of the Highest Cited Articles from Turkey}

The top 10 most cited articles contributed by Turkish scholars in each category are listed in Table V. There are only 3 articles that had $>10$ citations in Category 4 and there were none in Category 5. Among the 33 highly cited articles, 13 were multinational and only 2 of them did not have a Turkish first or last name author. The article types and numbers were: retrospective clinical study $(13 / 33,39 \%)$, laboratory studies $(6 / 33,18 \%)$, prospective clinical studies $(5 / 33,15 \%)$, reviews (3/33, 9\%), anatomical studies $(3 / 33,9 \%)$, novel operative techniques $(2 / 33,6 \%)$, and randomized controlled trials $(1 / 33$, $3 \%)$.

\section{DISCUSSION}

\section{Methodology}

Analyzing worldwide productivity for the main neurosurgical journals is not a new idea and has been previously considered $(2,11,20)$. The main motivation to conduct this study was a new feature of the WOS database that was recently activated for public users; i.e., the "Analyze Results" feature. This feature allowed extraction of data from a selected field (Countries/ Regions, Organizations, etc.) and then production of a report showing the values in ranked order. Before this feature, it was still possible to analyze these values and rank them, but every variable had to be typed manually. Sasaki et al. performed such a study (20) using the WOS database before the "Analyze Results" feature became available in 2011. They had chosen nine countries and then analyzed their results. They might or might not have chosen the top nine countries correctly, but the problem was they did not clarify how they chose those countries for a world ranking and yet named them "major countries."

Another similar study, also published in 2011 by Hauptman et al., (11) used a different methodology and database (MEDLINE). Instead of analyzing specific neurosurgical journals, they used a method that analyzed the publications of neurosurgeons. One of the limitations of their study was that 
Table IV: Department Rankings

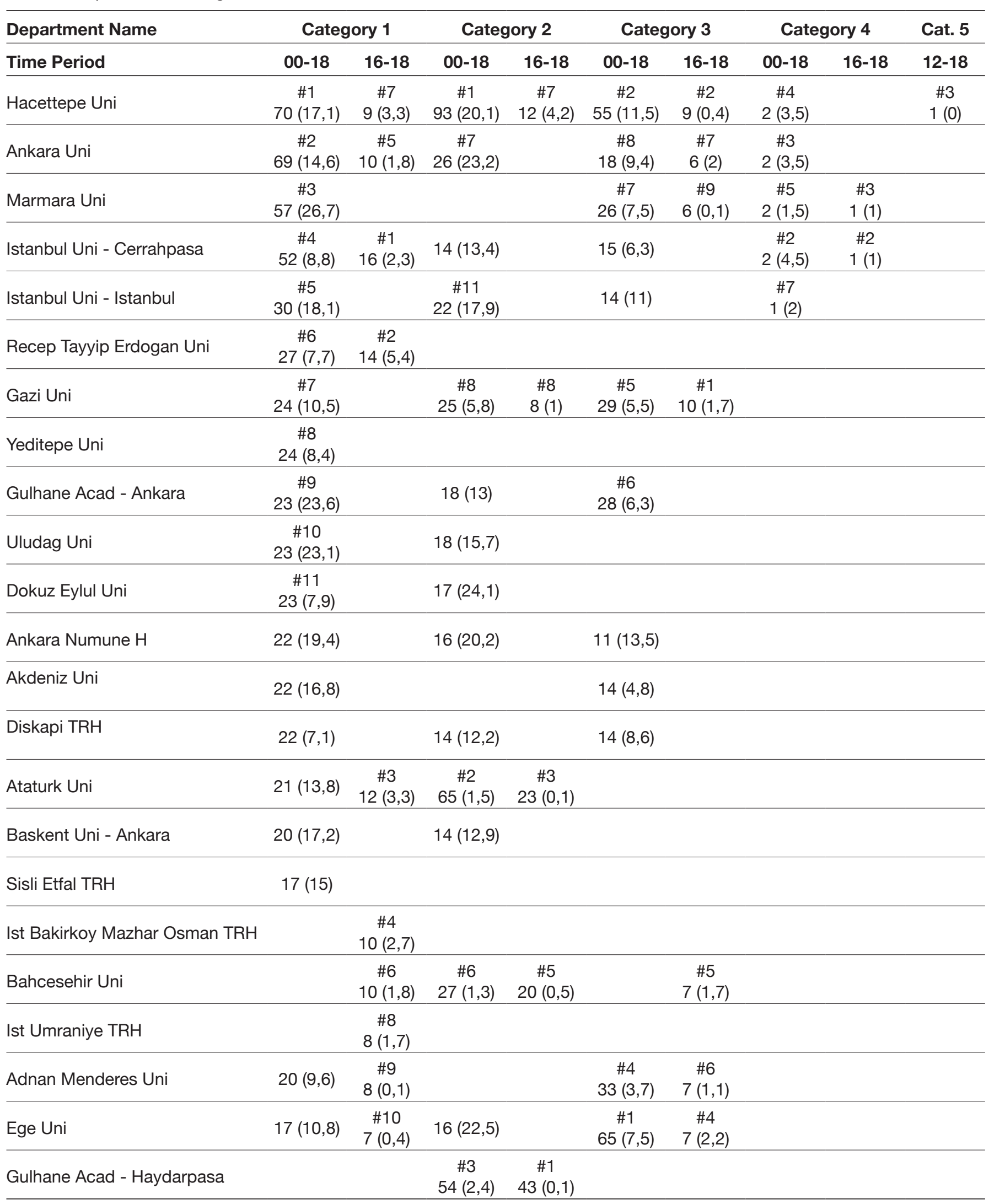


Sarica C. and Egemen E: Contribution of Countries to Neurosurgical Journals

Table IV: Cont.

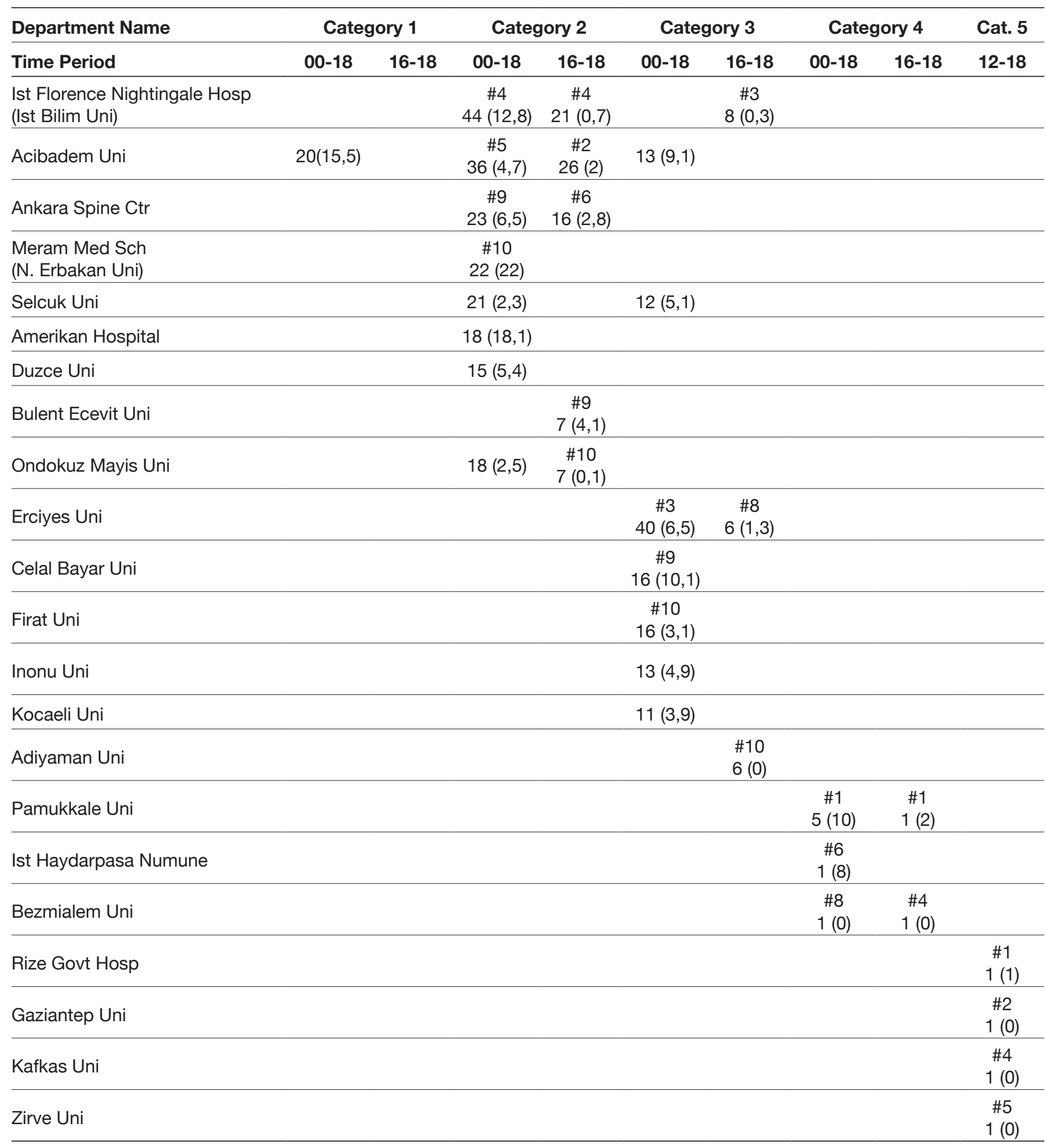

In the first line, the rank is given after hash symbol (\#). In the second line, first the publication count without parenthesis, then the average citation per item in parenthesis is given.

Contributions of the institutions that were more than $2 \%$ of the total articles in the Category 1, Category 2 and Category 3 for the period between 2000 and 2018, are listed. 
Table V: Top 10 Most Cited Articles by Turkish Scholars In Each Category

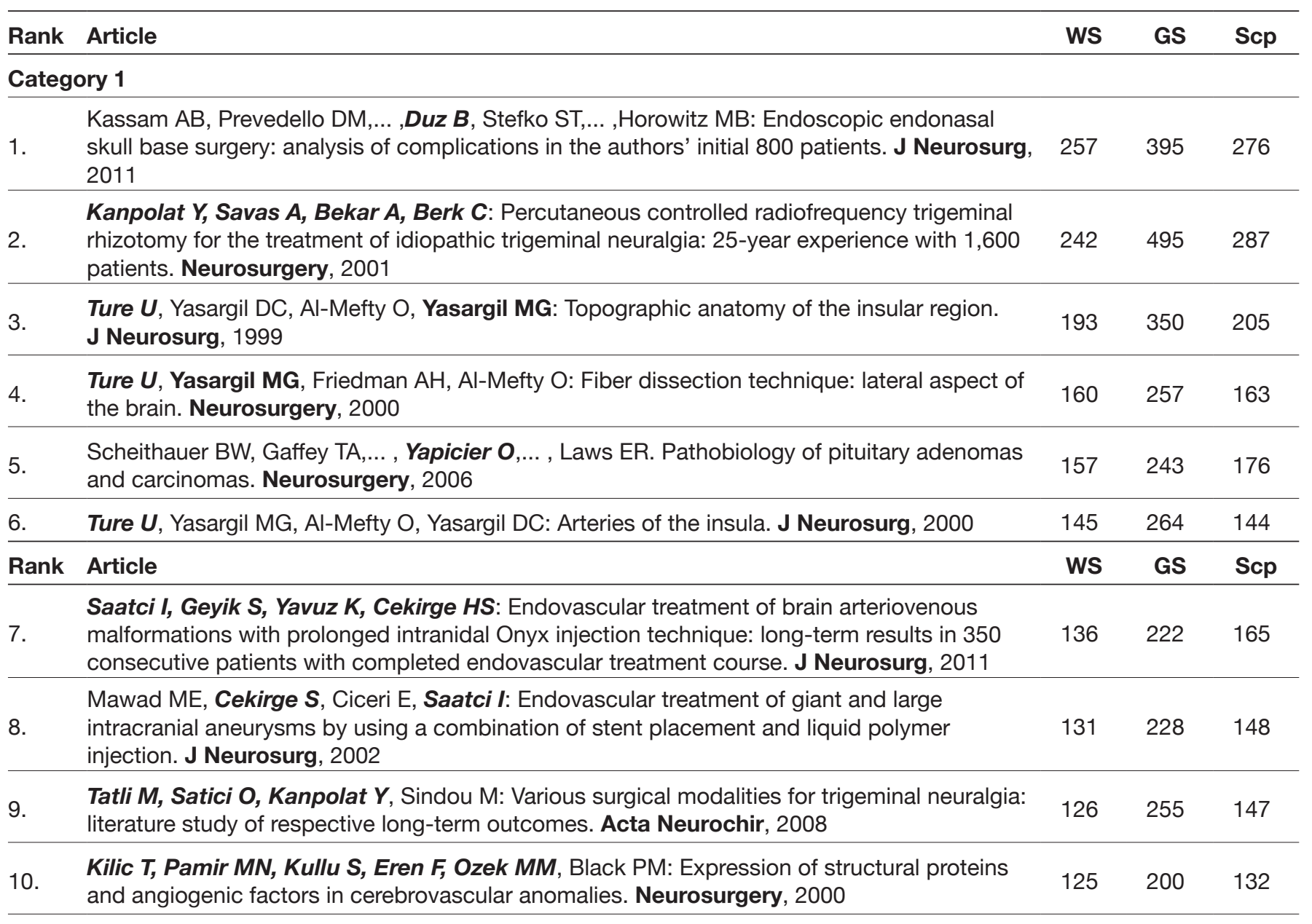

\section{Category 2}

1. Acaroglu ER, latridis JC, Setton LA, Foster RJ, Mow VC, Weidenbaum M: Degeneration and

2. Naderi S, Crawford NR, Song GS, Sonntag VK, Dickman CA: Biomechanical comparison of

2. C1-C2 posterior fixations. Cable, graft, and screw combinations. Spine, 1998

$175 \quad 298 \quad 192$

$158 \quad 261 \quad 170$

Alanay A, Acaroglu E, Yazici M, Oznur A, Surat A: Short-segment pedicle instrumentation

3. of thoracolumbar burst fractures: does transpedicular intracorporeal grafting prevent early failure? Spine, 2001

Yakut E, Duger T, Oksuz C, Yorukan S, Ureten K, Turan D, Frat T, Kiraz S, Krd N, Kayhan

4. $\quad \boldsymbol{H}$, Yakut $\boldsymbol{Y}$, Guler $\boldsymbol{C}$ : Validation of the Turkish version of the Oswestry Disability Index for $125 \quad 200 \quad 128$ patients with low back pain. Spine, 2004

$155 \quad 605 \quad 221$

\section{Gezen F, Kahraman S, Canakci Z, Beduk A: Review of 36 cases of spinal cord meningioma.}

5. Spine, 2000

6. Levendoglu F, Ogun CO, Ozerbil O, Ogun TC, Ugurlu H: Gabapentin is a first line drug for the treatment of neuropathic pain in spinal cord injury. Spine, 2004

$121248 \quad 150$

\section{Sirvanci M, Bhatia M, Ganiyusufoglu KA, Duran C, Tezer M, Ozturk C, Aydogan M,}

7. Hamzaoglu A: Degenerative lumbar spinal stenosis: correlation with Oswestry Disability Index and MR imaging. Eur Spine J, 2008

8. Cil A, Yazici M, Uzumcugil A, Kandemir U, Alanay A, Alanay Y, Acaroglu RE, Surat A:

8. The evolution of sagittal segmental alignment of the spine during childhood. Spine, 2005

$107 \quad 188 \quad 122$

$93 \quad 189 \quad 111$


Table V: Cont.

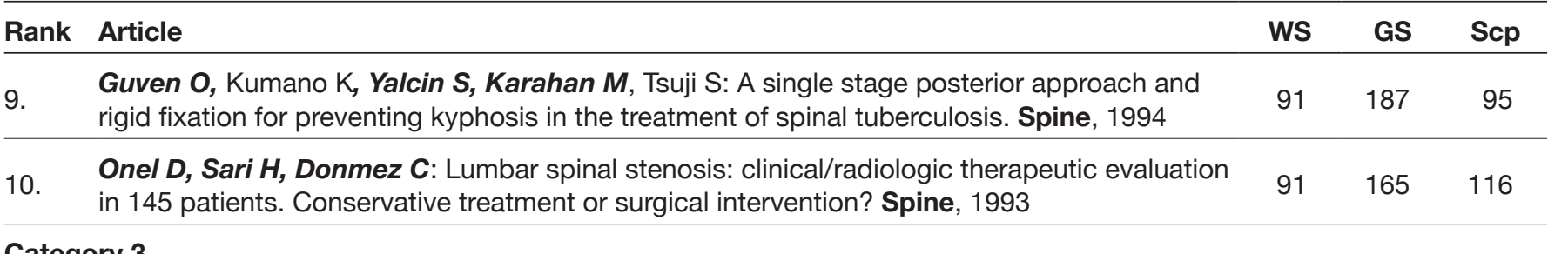

\section{Category 3}

Solaroglu I, Solaroglu A, Kaptanoglu E, Dede S, Haberal A, Beskonakli E, Kilinc K:

1. Erythropoietin prevents ischemia-reperfusion from inducing oxidative damage in fetal rat $82 \quad 149 \quad 100$ brain. Childs Nerv Syst, 2003

Tekkok IH, Erbengi A: Management of brain abscess in children: review of 130 cases over a period of 21 years. Childs Nerv Syst, 1992

3. Selcuki M, Vatansever S, Inan S, Erdemli E, Bagdatoglu C, Polat A: Is a filum terminale

3. with a normal appearance really normal? Childs Nerv Syst, 2003

75

4. Ozek MM: Complications of central nervous system hydatid disease. Pediatr Neurosurg, 1994

5. Ersahin Y, Arslan D: Complications of endoscopic third ventriculostomy. Childs Nerv Syst, 2008

6. Tufan K, Dogulu F, Kurt G, Emmez H, Ceviker N, Baykaner MK: Intracranial meningiomas of childhood and adolescence. Pediatr Neurosurg, 2005

$57 \quad 95 \quad 61$

$42 \quad 70 \quad 56$

Daglioglu E, Cataltepe O, Akalan N: Tectal gliomas in children: the implications for natural

7. history and management strategy. Pediatr Neurosurg, 2003

8. Turgut M: Transient "cerebellar" mutism. Childs Nerv Syst, 1998

$41 \quad 69 \quad 46$

$41 \quad 65 \quad 44$

Bilginer B, Oguz KK, Akalan N: Endoscopic third ventriculostomy for malfunction in

9. $\quad$ previously shunted infants. Childs Nerv Syst, 2009

Bilginer B, Yalnizoglu D, Soylemezoglu F, Turanli G, Cila A, Topcu M, Akalan N: Surgery

10. for epilepsy in children with dysembryoplastic neuroepithelial tumor: clinical spectrum, seizure outcome, neuroradiology, and pathology. Childs Nerv Syst, 2009

\section{Category 4}

1. Islekel S, Zileli M, Zileli B: Unilateral pallidal stimulation in cervical dystonia. Stereotact Funct Neurosurg, 1999

$40 \quad 58 \quad 46$

Acar F, Miller J, Golshani KJ, Israel ZH, McCartney S, Burchiel KJ: Pain relief after cervical

2. ganglionectomy (C2 and $\mathrm{C} 3$ ) for the treatment of medically intractable occipital neuralgia.

19

30

24 Stereotact Funct Neurosurg, 2008

Acar G, Acar F, Miller J, Spencer DC, Burchiel KJ: Seizure outcome following transcortical

3. selective amygdalohippocampectomy in mesial temporal lobe epilepsy. Stereotact Funct Neurosurg, 2008

MEDLINE only allows analyzing the first author's affiliation and country. Therefore, it is expected that they undercounted the contribution of non-first authors from different countries. They also probably missed the papers in which neurosurgeons were involved but whose department was not represented by the first author. Additionally, the first author could be a neurosurgeon but her/his affiliation could be a neurological institute or spine center instead of a neurosurgery department, so that study could easily be missed with limited search parameters. Another limitation is that neurosurgeons do not always write about neurosurgery. For example, a neurosurgeon can write about medical education, ethics, and the history of medicine in non-neurosurgical journals and such a research methodology may add these kinds of publications to studies regarding global research productivity in neurosurgery.

We believe our study that used this unique methodology with the new feature of WOS database overwhelmed such methodological limitations in previous studies and may serve as a model for future studies, even in different fields. Nevertheless, this methodology is still not limitationfree. Specialists from many different fields (pediatricians, 
orthopedicians, radiologists etc.) contribute to neurosurgical journals and, unfortunately, there is no simple method in the WOS database for public users to simply analyze the ratio of these contributions. Another limitation is there is the possibility of skipping a high-impact neurosurgical journal with inadequate keywords. We aimed to keep our keywords as extensive as possible but this did not remove the risk. Among the identified journals, we excluded the ones that had at least half of its publications not directly related to neurosurgery, or did not include original articles. We preferred to categorize the included journals and analyze them together instead of analyzing each journal separately. This is because North American countries dominate in journals like the Journal of Neurosurgery, or European countries dominate in Acta Neurochirurgica. We therefore found it more logical to categorize and analyze them together.

We only analyzed the papers that had been published in the current millennia and also the data of the last three years for every country to have an idea about trends, since we could not analyze all countries in detail, except for Turkey. It is easy to calculate the h-indexes of countries as a quality of productivity analysis using the WOS database. However, we did not prefer to do that since the $\mathrm{h}$-index is a time-dependent measure. It is expected for a country that published most of its publications early in this millennium to have a higher $\mathrm{h}$-index than a country that had publications later in the given time period, even if their publications had equal impacts. Instead, we chose to give average citation counts per item for all countries, which allows calculation of the total citations.

\section{Worldwide Contribution to Main Neurosurgical Journals}

The USA (35\%) was the largest overall contributor to the main neurosurgical journals, followed by Japan (7.7\%), Germany (5.3\%), China (5.3\%), Canada (4.4\%), England (3.5\%), Italy (3.4\%), South Korea $(2.9 \%)$, France $(2.6 \%)$, and Turkey $(2.5 \%)$. It is important to note that our study only analyzed contributions to the main neurosurgical journals, and not the overall research productivity of world neurosurgeons. As mentioned previously, Hauptman et al. (11) aimed to analyze the neurosurgeons' contributions to global research productivity and further analyzed the neurosurgical articles. They found the leading contributors to all neurosurgery articles were the USA (31.7\%), Japan (20.2\%), Germany (6.3\%), the United Kingdom (6.1\%), China (4.2\%), Turkey (4\%), Canada (3.6\%), Italy (3\%), South Korea (2.2\%), and India (2.1\%). As can be seen, the contribution rates of countries to main neurosurgical journals and to overall neurosurgery literature are almost identical, except for Japan. This can be interpreted as Japanese neurosurgeons having a higher publication count in journals other than the selected ones in this study.

\section{Factors that may Affect the Research Productivity and Strategies to Improve Research Productivity}

We herein discuss the factors that can be capable of influencing the contribution rate of a country to neurosurgical journals, and strategies to improve neurosurgical research productivity.

\section{Population of a country}

It may be expected that the population of a country is directly proportional to its research capacity. According to the "World Population Prospects: the 2019 Revision,"(25) among the top 10 most populous countries, only China (1433 M population) and the USA (329 M) are among the top 10 contributors in neurosurgical journals. India, with a $1366 \mathrm{M}$ population, contributes to $2 \%$, Brazil with a $211 \mathrm{M}$ population contributes to $1.1 \%$ and the remaining 6 most populous countries (Indonesia, Pakistan, Nigeria, Bangladesh, Russia and Mexico) with a total of $1124 \mathrm{M}$ population contributes to a total of $0.6 \%$ of publications in main neurosurgical journals. On the other hand, Canada, with a $37 \mathrm{M}$ population, is ranked in the top 10 with a $4.4 \%$ contribution. Both the Netherlands, with a $17 \mathrm{M}$ population, and Switzerland, with an $8 \mathrm{M}$ population, have a contribution ratio of $1.8 \%$ for each. Therefore, it is hard to say a direct proportion exists between a country's population and neurosurgical research.

\section{Total wealth of a country}

The top 10 countries in the world by total wealth holdings (1) almost totally overlaps with the top 10 contributors to neurosurgery journals, except for India and Australia, which ranked $11^{\text {th }}$ and $14^{\text {th }}$ in our study with $2 \%$ and $1.5 \%$ contribution rates, respectively. These two countries were replaced by South Korea and Turkey in our list. Adequate research funding and establishing high-quality research institutions are among the dominant factors that determine research productivity (12) and the financial needs for these factors can be more readily met by wealthy countries.

\section{Governmental and industrial support for research}

It is important to realize that there is a positive feedback loop between economic growth and research investment. The value of the positive effects of medical research, in the form of improved health and economic growth, mostly exceeds the costs of research investments (19). This information leads some governments and private investigators (medical device and pharmaceutical companies etc.) to invest in medical research, and this may contribute positively to research productivity in that country.

Here we give examples of the current status of medical research investments in different countries. The total amount that the United States spent on medical research and development in 2016 was $\$ 171,802 \mathrm{M}$, and there was a $20.6 \%$ growth in investments from 2013 to 2016 (17).

On the other hand, the Scientific and Technological Research Council of Turkey (TUBITAK), the governmental grantproviding agency of Turkey, has an annual budget of roughly \$100-200 M for new scientific projects in all fields, (23) and there were 168,583 academicians actively working in Turkey from all scientific fields by 2019 (9). If the grants were equally provided to all academicians, every academician would get around $\$ 1000$ for a year. If we consider that the overall cost of a randomized controlled trial ranges between \$0.2-611.5 $\mathrm{M},(21)$ we can easily understand the difficulty of performing these kinds of studies in Turkey. It is obvious that an increment 
in investment is obligatory for production of high-impact research in our case. If it is not possible in the short term, we have to at least take some precautions in funding. Instead of dividing the limited amount of money into thousands of low profile research studies, larger scale studies that may have a higher impact can be promoted. Instead of buying similar laboratory equipment separately for every laboratory, joint laboratories with higher technology may be established.

4. Investigator quality, effective neurosurgical training, and the abundance of role models

Human capital is a collection of traits-all the knowledge, talents, skills, abilities, experience, intelligence, training, judgment, creativity, and wisdom possessed individually and collectively by individuals in a population (6). Human capital development in neurosurgery is vital for maintaining high-quality patient care, effective neurosurgical research, and training new neurosurgeons. Increases in research funding per se will not produce proportionate changes in neurosurgical research output in the absence of a welldeveloped neurosurgical community in a particular country. Therefore, investment to improve neurosurgical research in a country should begin with establishing a well-educated pool of neurosurgeons.

Details of a high-quality neurosurgery education can easily be the topic of a separate article, but in summary, it has to provide the trainee both an adequate theoretical education and a suitable environment to improve his/her procedure experience, and it has to comprise both patient care and research. The presence of senior role models, mentoring, and support may clear the paths for young trainees, and well-educated trainees can maintain this cycle for future generations of neurosurgeons. In short, independent from the research investment in terms of funding, neurosurgeons are an asset to be invested in, and establishing a well-educated neurosurgical community is a prerequisite for effective neurosurgical research production.

Establishing a well-educated neurosurgeon pool, providing them a sufficient amount of funding, and supporting them with strong government policies are the gateway to high-impact neurosurgical research. What if a country has adequate quantity and quality of neurosurgeons but a limited amount of such research supporting governmental policies and strong grant programs? Can it still be research productive? We believe the answer is "yes, but limited," and Turkey is a good example. A country can still contribute densely to neurosurgical knowledge with low- and middle-cost studies like anatomical studies, retrospective case series, reviews and meta-analyses, and to some extent, prospective clinical studies and laboratory studies. However, at the edge of the 2020s, expecting a high-impact study in the absence of strong grants and research policies, or at least routinizing it, is not realistic. Turkey has been long contributing neurosurgical knowledge to a relatively good extent, but the impact is debatable.

In 2010, Ponce and Lozano reviewed the 100 top-cited papers in neurosurgical journals (15) and highly cited papers on neurosurgical topics (16). Lack of any single article from Turkey among these articles supports the inadequacy of Turkey in high-impact research production. This situation in Turkey is not specific to neurosurgery, but is seen in almost all fields of science. Scientists from "Science Academy, Turkey" named this situation the "Middle Science Zone Trap" because of its resemblance to the "Middle Income Trap," which exists for some countries that make significant progress in reducing extreme poverty and experience structural change and growth, but then find it difficult to make the climb from being a middle-income country to achieving a high-income fully-developed status. It is possible to reach an average research production level with some minor and short-term strategies (monetary prizes to investigators for published papers, supporting international collaborations, scholarships for incoming and out-going researchers etc.), but to be in the champion league of researchers, long term national research policies and a strong research investment are necessary.

5. Investigators' motivation for research and regulations of academic promotions

The motivation of a scientist for research can be gathered into three groups; (1) economical yields, (2) academic promotions, and (3) curiosity and passion for research. In the case of Turkey, unfortunately, the direct economical yield for a clinician carrying out a research project is easily a negligent amount and it barely covers the expenses of publication. Most of the research has been conducted for personal professional promotion and advancement. This is the likely reason why we mostly observe a severe decrement in the research productivity of researchers after they reached the highest academic degrees if they lack the sole long term motivation for research; that is, curiosity and passion.

Academic promotion regulations strongly influence research productivity. Current academic promotion regulations in Turkey are solely dependent on the quantity of articles, following the new regulation changes in 2016, and ignoring the quality of the published papers. Such regulations might cause Turkey addressed articles to published dominantly in third and fourth quartile journals. We searched the WOS database for "Turkey" addressed articles in all fields between 2017 and 2019, and checked the top 100 journals in terms of publication counts that Turkish scholars preferred to publish their research in. We found out that only $22 \%$ of the journals were in the first and second quartile (Q1:12, Q2:10, Q3:13, Q4:30, ESCl: 26, Conference:9). For a comparison, the same ratios were $93 \%$ for the USA (Q1:77, Q2:16, Q3:1, Q4:1, ESCl: 1, C:4); 87\% for England (Q1:73, Q2:14, Q3:3, Q4:3, ESCI: 1, C:6); 86\% for Canada (Q1:71, Q2:15, Q3:2, Q4:5, ESCI: 2, C:5); 80\% for Germany (Q1:65, Q2:15, Q3:2, Q4:8, ESCI: 0, C:10); 70\% for China (Q1:50, Q2:20, Q3:10, Q4:5, ESCl: 0, C:15); and 65\% for Japan (Q1:46, Q2:19, Q3:17, Q4:10, ESCI: 1, C:7). In short, academic promotions solely depend on quantity and ignoring quality may improve research productivity to some extent, but more efficient regulations are needed for further improvement.

6. Time for research; investigators' clinical workload and the amount of full-time researchers 
The amount of time spent on research is an important factor that may influence research productivity. Dewan et al. recently published an article regarding the current capacity and deficit in the provision of essential neurosurgical care and gave world maps of deficits of neurosurgical care by analyzing the annual essential case consultations and surgical cases per neurosurgeon in every country (10). They indicated that less than 500 cases per neurosurgeon yearly is an adequate ratio of the availability of neurosurgeons in that country. They determined that the annual essential case consultations per neurosurgeon is higher than 500 cases in Canada, the United Kingdom, France, India and the Netherlands, which were among the top contributors to neurosurgical journals. This may reflect the greater clinical needs of the neurosurgeons in those countries that supplant time for research and put them in a disadvantageous position in research productivity. This ratio is lower and adequate in the other top 10 contributor countries of neurosurgical journals. In contrast, there are also countries that are not in a shortage of neurosurgeons in terms of numbers but have a poor contribution ratio to neurosurgical research.

Employing full-time researchers or collaborating with them in a multidisciplinary fashion may increase research productivity (8). Having a dual career (a PhD degree in basic sciences with a clinical subspecialization) is a common tradition among clinicians in research active countries. For a clinician, taking a break from clinical work and spending time on research, as an example, during residency training or in completion of a $\mathrm{PhD}$ thesis, may contribute to research productivity in a positive manner.

\section{The national tradition of research productivity}

Countries with higher research productivity generally understand the importance of new discoveries for the future and this is true for neurosurgical research as well. There is a likely positive relationship between basic sciences and neurosurgical research performance. The Nature Index (NI), (7) a database that tracks the affiliations of high-quality scientific articles published in 82 science journals independently chosen by the scientific community, provides annual league tables of research output for countries worldwide. As expected, the top 10 countries in NI 2019 for all basic sciences were also the top 10 contributors to the main neurosurgical journals, except for Italy and Turkey. Italy is ranked $12^{\text {th }}$ in the NI 2019 and is just a few articles from being listed in the top 10. On the other hand, Turkey is ranked $39^{\text {th }}$ in the NI 2019. Therefore, it is difficult to suggest that Turkey's relatively high contribution to neurosurgical journals is a reflection of its overall scientific productivity.

8. Scientific reputation of a country, scientific misconduct and the importance of establishing national journals

As neurosurgical researchers, we must achieve and maintain research integrity since we provide knowledge that may impact people's lives. Some researchers prefer to commit scientific misconduct in the form of fabrication, falsification, and plagiarism in search of promotion, tenure, status, and obtaining a grant. Receiving many suspicious studies from particular countries by editors may damage the scientific reputation of those countries and result in formation of a prejudice against all the manuscripts received from that country.

We believe every country must establish its own system to detect and prevent such scientific misconduct. This may raise the quality and integrity of science in that country, resulting in an increment in the international publication counts and prevent wasting of money invested in misconducted research.

Additionally, establishing a local journal will facilitate a decrease in fraud. As an example, a clinical investigator can prefer to publish his/her case series much the same in a local journal instead of exaggerating the patient numbers and outcomes for publication in a high-impact international journal.

9. Quality of universities, scientific institutions and medical faculties

There is an expected probable correlation between the countries that have a top 100 ranked university with a medical faculty in The Times Higher Education World University Rankings 2020 list and top publisher countries for neurosurgical journals (24). All the countries in our list had at least one university in the top 100 university list, except for Italy and Turkey. Moreover, while Italy has 21 universities with medical faculties, Turkey has none in the top 500 universities list.

As of 2019, there were 207 universities with 101 medical schools and 89 separate specialty training and research hospitals in Turkey (9). The medical school per population ratio of Turkey for 2019 is 1 in 826,035. The ratio was 1 in $1,577,826$ for Europe and 1 in 1,859,581 for the USA in 2014, which means the density of medical schools in Turkey is almost two times higher than in Europe and even higher than in the USA (18). Founding a medical faculty for every single city in a country may provide an advantage in patient care, but it is obvious from the world university rankings data that it decreases the overall quality, especially in terms of highimpact research production.

\section{International collaboration}

The ratio of internationally collaborative articles in international journals increased to over a third from a quarter in the last 15 years (26). Collaboration enhances the quality of scientific research, improves the efficiency and effectiveness of that research, and is increasingly necessary, as the scale of both budgets and research challenges grow. Collaboration brings significant benefits, both measurable (such as increased citation impact and access to new markets) and less easily quantifiable, such as broadening research horizons (26).

\section{Obtaining new technologies}

Inventing or early employment of new drugs/technologies by a country would favor the performance of clinical investigation with that invention in the country. As a simple example, relatively early establishment of a Gamma Knife unit in 1997 in Turkey was related to the Gamma Knife research production originating from Turkey (13). In comparison, Turkey 
has not been able to contribute the clinical investigation of new technologies, such as laser induced thermal therapy, or magnetic resonance guided focus ultrasonography as a result of not securing them yet.

\section{Regulatory challenges in research}

Some countries may be more advantageous over the others in terms of regulatory challenges of research. The stringency level of Institutional Review Boards may differ from country to country. Some experiments may be performed with a lower cost because of the lower costs of clinical trial insurance policies, or for many other reasons. Identification and enrollment of patients in clinical trials, and obtaining administrative approval (i.e., FDA, CE), may have different difficulty levels among countries.

\section{Political and economic stability of a country}

The political and economic stability of a country are prerequisites for maintaining a peaceful environment for an investigator to focus on more difficult, perhaps longer-range research goals. Turkey may again be an example in this regard. There was a positive momentum of contribution to neurosurgical journals for Turkey between 2013 and 2016, which peaked at 2016. This peak may be related to the 2015 announcement of new regulations for academic promotions, which were to be in effect at the end of 2016 and harden the criteria to become an associate professor. The rush of academicians, who wanted to be considered under older regulations, might have led to an all-time peak. However, the contribution rate of Turkey dropped dramatically, from $4.5 \%$ to $1.9 \%$, in the following year. The political instability in 2016 (coup attempt, terror attacks etc.) may have contributed to this sharp fall. We can conclude that political and economic stability of a country is a sine qua non for higher and more impactful research productivity.

\section{Proficiency in English language}

This is one of the common problems among neurosurgeons of non-English-speaking countries. A clinician needs to know English at least to a B2 level to comprehend the medical literature in English, and a little higher level may be required to write his/her scientific articles. Luckily, professional language editing services are helping the non-native English-speaking clinicians with fine-tuning and solving the problem to some extent. However, this still requires at least a B2-C1 level of English for the clinician.

It is very challenging for a clinician to improve his/her English language skills from the A1-2 levels to B2-C1 levels in his/her mid-30s under heavy clinical workloads, so this knowledge has to be taught before the beginning of a professional career, particularly in or before elementary school. An insufficient English education may cause a clinician to be unable to develop skills to follow the international literature, and they are then limited to only literature in his/her native language. The impact and yield of publishing in local non-English languages is lower compared to international publishing, and that may easily result in disenchantment of the clinician from scientific research.

\section{CONCLUSIONS}

This bibliometric assessment of neurosurgical journals allows countries to perceive their neurosurgical research productivity. It can function as a benchmark for academic productivity and the methodology can be a model for particular analysis of other countries.

\section{ACKNOWLEDGMENTS}

Preparation for publication of this article is partly supported by Turkish Neurosurgical Society.

\section{FUNDING}

This research did not receive any specific grant from funding agencies in the public, commercial, or not-for-profit sectors.

\section{REFERENCES}

1. AfrAsia Bank: Global Wealth Migration Review https:// www.afrasiabank.com/en/about/newsroom/global-wealthmigration-review-2019. 2019

2. Akhaddar A: Contribution of Moroccan neurosurgeons to the World neurosurgical literature in PubMed. A bibliometric evaluation over times. World Neurosurg 126:59-65, 2019

3. Altinors N, Comert S, Sonmez E, Altinel F: Turkish contribution to Journal of Neurosurgery and Acta Neurochirurgica. Turk Neurosurg 27:1007-1015, 2017

4. Arslantas A, Naderi S: The contribution of Turkish neurosurgeons to Spine surgery literature. Turk Neurosurg 15:45-51, 2005

5. Black PM: Challenges in contemporary academic neurosurgery. Neurosurgery 58:419-425, 2006

6. Bozeman B, Dietz JS, Gaughan M: Scientific and technical human capital: An alternative model for research evaluation. Int J Technol Manag 22:716-740, 2001

7. Campbell N, Grayson M: The Nature Index https://www. natureindex.com. 2019

8. Carayol N, Matt M: Individual and collective determinants of academic scientists' productivity. Inf Econ Pol 18:55-72, 2006

9. Council of Higher Education Turkey: https://istatistik.yok.gov. tr. 2019

10. Dewan MC, Rattani A, Fieggen G, Arraez MA, Servadei F, Boop FA, Johnson WD, Warf BC, Park KB: Global neurosurgery: The current capacity and deficit in the provision of essential neurosurgical care. Executive Summary of the Global Neurosurgery Initiative at the Program in Global Surgery and Social Change. J Neurosurg, 2018 (Online ahead of print)

11. Hauptman JS, Chow DS, Martin NA, Itagaki MW: Research productivity in neurosurgery: Trends in globalization, scientific focus, and funding. J Neurosurg 115:1262-1272, 2011

12. Kern S: Analytic model for academic research productivity having factors, interactions and implications. Cancer Biol Ther 12:949-956, 2011

13. Kilic T, Peker S, Pamir MN: Gamma-knife radiosurgery. Turk Norosir Derg 10:119-136, 2000 
14. Ormond DR, Hadjipanayis CG: The history of neurosurgery and its relation to the development and refinement of the frontotemporal craniotomy. Neurosurg Focus 36:E12, 2014

15. Ponce FA, Lozano AM: Highly cited works in neurosurgery. Part I: The 100 top-cited papers in neurosurgical journals. J Neurosurg 112:223-232, 2010

16. Ponce FA, Lozano AM: Highly cited works in neurosurgery. Part II: The citation classics. J Neurosurg 112:233-246, 2010

17. Research! America: U.S. Investments in Medical and Health Research and Development, 2013-2016. https:// www.researchamerica.org/sites/default/files/RA-2017_ InvestmentReport.pdf 2017

18. Rigby PG, Gururaja RP: World medical schools: The sum also rises. JRSM Open 8:2054270417698631, 2017

19. Roback K, Dalal K, Carlsson P: Evaluation of health research: Measuring costs and socioeconomic effects. Int J Prev Med 2:203-215, 2011

20. Sasaki T, Hashiguchi K, Yoshimoto K, Nakamizo A, Mizoguchi M, Neurosurgical Staff of Kyushu University: Worldwide academic contributions of Japanese neurosurgeons. Neurol Med Chir 51:405-414, 2011
21. Speich B, von Niederhausern B, Schur N, Hemkens LG, Furst T, Bhatnagar N, Alturki R, Agarwal A, Kasenda B, Pauli-Magnus C, Schwenkglenks M, Briel M, Group MARTA: Systematic review on costs and resource use of randomized clinical trials shows a lack of transparent and comprehensive data. J Clin Epidemiol 96:1-11, 2018

22. Tekkok IH, Acikgoz B: Publications from Turkey in European and American neurosurgical journals - A review of the facts. Turk Neurosurg 4:106-110, 1994

23. The Scientific and Technological Research Council of Turkey (TUBITAK): http://www.tubitak.gov.tr/tr/destekler/ akademik/ulusal-destek-programlari/icerik-akademik-destekistatistikleri. 2019

24. The Times Higher Education World University Rankings: https://www.timeshighereducation.com/world-universityrankings. 2020

25. United Nations Econ Soc Aff: World population prospects: The 2019 revision. https://population.un.org/wpp/. 2019

26. Wilsdon J: Knowledge, networks and nations: Global scientific collaboration in the 21st century. London: The Royal Society, 2011 